\title{
STUDI SISTEM DRAINASE PERGUDANGAN PAJANG KOTA TANGERANG
}

\author{
Fuad Hasan', R.H.B. Ash Siddiq², Yanyan Agustian³ \\ Program Studi Teknik Sipil, Fakultas Teknik \\ Universitas Widyatama \\ Jalan Cikutra no 204A, Kota Bandung \\ hasan.fuad@widyatama.ac.id ${ }^{1}$, raden.herdian@widyatama.ac.id ${ }^{2}$, yanyan.agustian@widyatama.ac.id ${ }^{3}$
}

\begin{abstract}
Abstrak
Di daerah Pajang, Kota Tangerang, sebelah selatan Bandara Soekarno-Hatta akan dibangun sentra pergudangan dengan luas $\pm 6 \mathrm{Ha}$. Lahan yang ada merupakan lahan kosong yang belum dilengkapi sistem drainase. Berdasarkan kaidah teknis serta kebijakan-kebijakan pemerintah setempat yang berhubungan dengan sistem tata air perkotaan dan pengendalian banjir, perlu dicari solusi yang tepat untuk meminimalisir dampak yang akan terjadi akibat adanya pembangunan sarana tersebut tanpa mengganggu sistem tata air yang ada. Oleh karena itu, diperlukan suatu kajian teknis berupa Kajian Drainase Rencana Kawasan Pergudangan Pajang Kota Tangerang. Berdasarkan analisa yang telah dilakukan, jaringan saluran drainase yang direncanakan serta pembuatan kolam retensi di Kompleks Pergudangan Pajang dapat meminimalisir dampak banjir baik di Kawasan dalam pergudangan maupun Kawasan luar pergudangan.
\end{abstract}

Kata kunci : Sistem drainase, pengendalian banjir, kolam retensi

\section{Abstract}

In the Pajang area, Tangerang City, south of Soekarno-Hatta Airport, a warehousing center will be built with an area of \pm 6 hectares. The existing land is empty land that is not equipped with a drainage system. Based on technical principles and local government policies relating to urban water systems and flood control, it is necessary to find the right solution to minimize the impact that will occur due to the construction of these facilities without disturbing the existing water system. Therefore, a technical study is needed in the form of a Study on Drainage Plan for the Pajang Warehouse Area in Tangerang City. Based on the analysis that has been carried out, the planned drainage channel network and the construction of a retention pool in the Pajang Warehousing Complex can minimize the impact of flooding both in the area inside the warehouse and in the area outside the warehouse.

Keywords : Drainage system, flood control, retention pond

\section{Pendahuluan}

Di daerah Pajang, Kota Tangerang, sebelah selatan Bandara Soekarno-Hatta akan dibangun sentra pergudangan dengan luas $\pm 6 \mathrm{Ha}$. Lahan yang ada merupakan lahan kosong yang belum dilengkapi sistem drainase.

Berdasarkan kaidah teknis serta kebijakankebijakan pemerintah setempat yang berhubungan dengan sistem tata air perkotaan dan pengendalian banjir, perlu dicari solusi yang tepat untuk meminimalisir dampak yang akan terjadi akibat adanya pembangunan sarana tersebut tanpa mengganggu sistem tata air yang ada. Lahan eksisting merupakan lahan kosong yang belum dilengkapi sistem drainase. Oleh karena itu, diperlukan suatu kajian teknis berupa Kajian Drainase Rencana Kawasan Pergudangan Pajang Kota Tangerang.

\section{KAJIAN LITERATUR}

Lokasi kajian secara administratif berada di Kelurahan Pajang, Kecamatan Benda, Kota Tangerang, tepatnya di sebelah selatan Bandara Soekarno-Hatta.

Secara geografis, Lokasi kajian mempunyai batas wilayah :

- Sebelah selatan berbatasan Kecamatan Benda

Fuad Hasan, R.H.B. Ash Siddiq, Yanyan Agustian

Jurnal Ilmiah Teknologi Informasi Terapan

Volume 6, No 3, 15 Agustus 2020 
- Sebelah utara berbatasan Bandara SoekarnoHatta

- Sebelah timur berbatasan dengan kawasan pemukiman

- Sebelah barat berbatasan dengan perkebunan dan pemukiman

Untuk menganalisis kondisi hidrologi di wilayah kajian diperlukan data hujan dari stasiun pengamatan terdekat di sekitarnya.

Kajian hidrologi di lokasi studi akan menggunakan data hujan dari Stasiun BMKG No. 26a Cengkareng. Letak lokasi stasiun hujan ini berada sekitar $3.37 \mathrm{~km}$ di arah timur lokasi kajian. Data hujan harian maksimum yang tersedia di stasiun hujan tersebut adalah dari tahun 1969-2014.

Kondisi topografi lahan merupakan hal yang paling mendasar dalam perencanaan sistem tata air. Dari peta topografi kondisi kontur elevasi kawasan dapat diamati sehingga dapat ditentukan arah aliran air suatu sistem tata air yang terencana. Berdasarkan identifikasi lapangan, ada beberapa saluran eksisting milik Dinas Pekerjaan Umum dan Penataan Ruang.

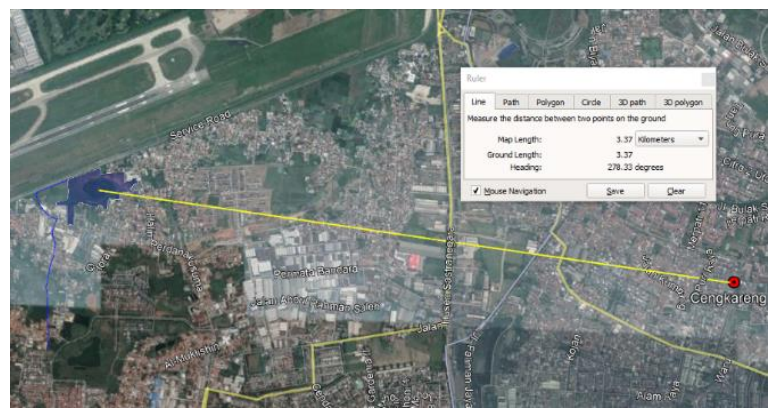

Gambar 1 Lokasi pekerjaan dan stasiun hujan

Site plan yang direncanakan yaitu merupakan pergudangan (lahan 1 sampai 12) dan lahan penghijauan (lahan A dan B) dengan luas keseluruhan $57.814 \mathrm{~m}^{2}$ yang dapat dilihat pada gambar berikut.

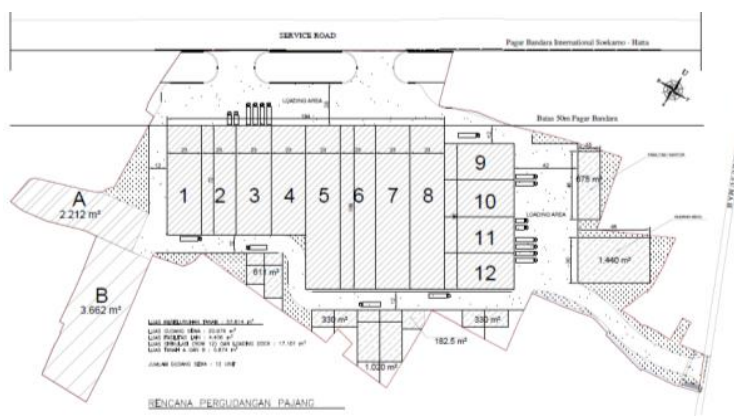

Gambar 2 Rencana site plan pergudangan Pajang

\section{ANALISIS DAN PERANCANGaN}

\section{III.1 Metodologi}

Metodologi yang digunakan dalam penelitian ini yaitu :

1. Persiapan

2. Pengumpulan data sekunder

3. Identifikasi lapangan

a) Survey kondisi drainase eksisting dan arah aliran

b) Survey topografi

4. Analisa data

a) Analisa hidrologi : curah hujan rencana dan intensitas hujan

b) Analisa hidrolika

5. Kesimpulan dan saran

\section{III.2 Keadaan Umum Lokasi Penelitian}

Penelitian yang dilakukan berada di berada di Kelurahan Pajang, Kecamatan Benda, Kota Tangerang, tepatnya di sebelah selatan Bandara Soekarno-Hatta dengan luas keseluruhan catchment sebesar \pm 58 ha dengan elevasi tanah rata-rata +8.37 mdpl, tanah tertinggi pada elevasi +9.607 mdpl dan tanah terendah pada elevasi $+6.827 \mathrm{mdpl}$. Rencana tata guna lahan pada lokasi penelitian didominasi oleh pergudangan.

\section{III.3 Analisa Curah Hujan Rencana}

Analisis dilakukan dengan menggunakan data curah hujan harian dari tahun 1969 hingga 2018 yang diperoleh dari pencatatan BMKG No. 26a Cengkareng. Curah hujan rencana dihitung berdasarkan data curah hujan harian maksimum selama 10 tahun yang dapat dilihat pada Tabel 1. 
Tabel 1 Data Curah Hujan Harian Maksimum 10 tahun

\begin{tabular}{|c|c|c|c|c|c|c|c|c|c|c|c|}
\hline No & Tahun & $\begin{array}{c}\text { CH Maksimal } \\
\text { (mm/hari) }\end{array}$ & No & Tahun & $\begin{array}{c}\text { CH Maksimal } \\
\text { (mm/hari) }\end{array}$ & No & Tahun & $\begin{array}{c}\text { CH Maksimal } \\
\text { (mm/hari) }\end{array}$ & No & Tahun & $\begin{array}{c}\text { CH Maksimal } \\
\text { (mm/hari) }\end{array}$ \\
\hline 1 & 1969 & 53 & 14 & 1982 & 60 & 27 & 1995 & 125 & 40 & 2008 & 317 \\
\hline 2 & 1970 & 56 & 15 & 1983 & 112 & 28 & 1996 & 107 & 41 & 2009 & 84 \\
\hline 3 & 1971 & 41 & 16 & 1984 & 93 & 29 & 1997 & 69 & 42 & 2010 & 106 \\
\hline 4 & 1972 & 40 & 17 & 1985 & 88 & 30 & 1998 & 90 & 43 & 2011 & 110 \\
\hline 5 & 1973 & 152 & 18 & 1986 & 139 & 31 & 1999 & 130 & 44 & 2012 & 101 \\
\hline 6 & 1974 & 130 & 19 & 1987 & 71 & 32 & 2000 & 103 & 45 & 2013 & 135 \\
\hline 7 & 1975 & 88 & 20 & 1988 & 74.1 & 33 & 2001 & 104 & 46 & 2014 & 104 \\
\hline 8 & 1976 & 151 & 21 & 1989 & 100 & 34 & 2002 & 88 & 47 & 2015 & 128 \\
\hline 9 & 1977 & 142 & 22 & 1990 & 110 & 35 & 2003 & 39 & 48 & 2016 & 148 \\
\hline 10 & 1978 & 60 & 23 & 1991 & 98 & 36 & 2004 & 114 & 49 & 2017 & 126 \\
\hline 11 & 1979 & 123 & 24 & 1992 & 110 & 37 & 2005 & 158.1 & 50 & 2018 & 85.4 \\
\hline 12 & 1980 & 86 & 25 & 1993 & 136 & 38 & 2006 & 60 & & & \\
\hline 13 & 1981 & 70 & 26 & 1994 & 85 & 39 & 2007 & 153 & & & \\
\hline
\end{tabular}

Perkiraan hujan rancangan didapatkan dari analisis frekuensi dengan kemungkinan tertinggi pada periode tertentu. Hasil analisis frekuensi berfungsi sebagai dasar perhitungan untuk mengantisipasi setiap kemungkinan yang akan terjadi. Menurut Widodo dan Ningrum (2015), data hidrologi yang diperlukan dalam perancangan drainase adalah data curah hujan dari stasiun

pencatat curah hujan di sekitar atau terdekat lokasi studi. Analisis frekuensi dapat dilakukan dengan metoda probability distribution antara lain Distribusi Normal, Distribusi Log Normal, Distribusi Log-Person III, dan Distribusi Gumbel (Triatmodjo 2010). Kala ulang yang digunakan untuk menghitung nilai hujan rencana yaitu 2, 5, 10, 25, dan 50 tahun. Hasil analisis frekuensi curah hujan rencana dapat dilihat pada Tabel 2.

Tabel 2 Hasil Analisis Curah Hujan Rencana

\begin{tabular}{cccc}
\hline $\begin{array}{c}\text { Periode Ulang } \\
\text { (tahun) }\end{array}$ & \multicolumn{3}{c}{ Curah Hujan Distribusi (mm) } \\
Normal & Gumbel & Log Pearson III \\
\hline \hline 2 & 103.6 & 96.2 & 96.3 \\
5 & 141.6 & 136.1 & 134.6 \\
10 & 161.5 & 162.6 & 159.8 \\
20 & 177.9 & 182.6 & 183.6 \\
50 & 196.4 & 187.9 & 220.8 \\
100 & 207.6 & 243.3 & 230.7 \\
1000 & 241.3 & 322.6 & 296.1 \\
\hline \hline
\end{tabular}

Hasil perhitungan nilai curah hujan rencana dari setiap metode memiliki nilai yang berbeda sehingga harus diuji kesesuaiannya dengan sifat masing-masing jenis distribusi. Hal ini dilakukan dengan melakukan tinjauan terhadap syarat batas parameter statistik tiap distribusi. Penentuan tipe distribusi dapat dilihat dari parameter-parameter statistik data pengamatan lapangan, yaitu nilai $\mathrm{Cs}$ dan $\mathrm{Ck}$. Perbandingan parameter distribusi probabilitas dapat dilihat pada Tabel 3.
Tabel 3 Resume Uji Distribusi

\begin{tabular}{|c|c|c|c|c|c|c|c|}
\hline Metode & \multicolumn{3}{|c|}{ Syarat } & \multicolumn{3}{|c|}{ Perhitungan } & \multirow{2}{*}{$\begin{array}{l}\text { Keterangan } \\
\text { Tidak memenuhi }\end{array}$} \\
\hline \multirow{3}{*}{ Normal } & Cs & $=$ & 0 & Cs & $=$ & 2.268849 & \\
\hline & $\mathrm{Ck}$ & $=$ & 0.570947 & $\mathrm{Ck}$ & $=$ & 13.01201 & Tidak memenuhi \\
\hline & & & & $\mathrm{Cv}$ & $=$ & 0.436252 & \\
\hline Log Pearson tipe III & $\mathrm{Cs}$ & $\neq$ & 0 & Cs & $\neq$ & 0.199 & Memenuhi \\
\hline \multirow{2}{*}{ Gumbel } & Cs & $=$ & 1.1396 & Cs & $=$ & 0.841 & Tidak memenuhi \\
\hline & $\mathrm{Ck}$ & $\leq$ & 5.4002 & $\mathrm{Ck}$ & $\leq$ & 3.43 & Memenuhi \\
\hline
\end{tabular}

Tabel 4 Resume Uji Chi Square

\begin{tabular}{|l|c|c|l|}
\hline \multicolumn{1}{|c|}{ Metode } & $\boldsymbol{\chi}$ terhitung & $\boldsymbol{\chi 2}$ cr & \multicolumn{1}{|c|}{ Keterangan } \\
\hline \hline Normal & 6.6522 & 14.86 & Diterima \\
\hline .Log Pearson III & 3.0000 & 14.86 & Diterima \\
\hline Gumbel & 2.0870 & 14.86 & Diterima \\
\hline
\end{tabular}

Tabel 5 Resume Uji Smirnov Kolmogorov

\begin{tabular}{|l|r|r|l|}
\hline \multicolumn{1}{|c|}{ Metode } & Dk terhitung & Dk cr & \multicolumn{1}{|c|}{ Keterangan } \\
\hline \hline Normal & 0.00016641 & 0.198 & Diterima \\
\hline Log Pearson III & 0.499363955 & 0.198 & Tidak Diterima \\
\hline Gumbel & 0.046423919 & 0.198 & Diterima \\
\hline
\end{tabular}

Dari hasil perhitungan maka diperoleh kesimpulan bahwa tidak ada distribusi probabilitas yang memenuhi semua syarat uji distribusi. Namun demikian, pemilihan distribusi didasarkan pada distribusi yang paling banyak memenuhi syarat, sehingga dipilih distribusi Gumbel sebagai metode perhitungan curah hujan rencana. Dalam menentukan curah hujan rencana, digunakan curah hujan dengan periode ulang 10 tahun, sehingga besarnya curah hujan rencana pada Kajian Drainase Kawasan Pergudangan Pajang adalah $163 \mathrm{~mm}$.

\section{III.4 Analisa Debit Banjir}

Pada daerah kajian Pergudangan Pajang tidak tersedia data debit aliran ekstrim. Untuk itu selanjutnya perhitungan debit banjir dihitung dengan bantuan perhitungan hujan limpasan dan software Storm Water Management Model (SWMM) untuk analisa hidrolika. Untuk menentukan debit banjir rencana dilakukan analisa debit puncak banjir dengan menggunakan metode Rasional.

$\mathrm{Q} \quad=0,00278 \times \mathrm{C} \times \mathrm{I} \times \mathrm{A}$

Dimana :

$\mathrm{Q}=$ Debit Banjir $\left(\mathrm{m}^{3} / \mathrm{dtk}\right)$

$\mathrm{C}=$ Koefisien Pengaliran

I = Intensitas Hujan Rata-rata ( $\mathrm{mm} / \mathrm{jam})$

A $\quad=$ Luas Daerah (ha)

Fuad Hasan, R.H.B. Ash Siddiq, Yanyan Agustian Jurnal Ilmiah Teknologi Informasi Terapan Volume 6, No 3, 15 Agustus 2020 
Tabel 6 Data Hidrologi

\begin{tabular}{|c|c|c|c|c|c|c|c|c|}
\hline \multirow[t]{2}{*}{ No } & \multirow[t]{2}{*}{ Nama DTA } & Luas DTA & $\begin{array}{c}\text { Panjang Sungai } \\
\text { Utama }\end{array}$ & $\begin{array}{l}\text { Koefisien } \\
\text { Pengaliran }\end{array}$ & $\mathrm{H}_{1}$ & $\mathrm{H}_{2}$ & $\Delta H$ & $\begin{array}{c}\text { Kemiringan } \\
\text { Rerata Sungai }\end{array}$ \\
\hline & & $\left(\mathrm{Km}^{2}\right)$ & $(\mathrm{Km})$ & (C) & (m) & $(\mathrm{m})$ & (m) & (l) \\
\hline \begin{tabular}{|l|l}
1 & \\
\end{tabular} & CA Gudang $6 \mathrm{Ha}$ & 0.06 & 0.60 & 0.900 & 9.61 & 8.09 & 1.51 & 0.00280 \\
\hline & & & Nama DPS & CA Gudang $6 \mathrm{Ha}$ & & & & \\
\hline & & & $\mathrm{H}_{1}=$ Elevasi Hulu (m) & 9.61 & & & & \\
\hline & & & $\mathrm{H}_{2}=$ Elevasi Hilir (m) & 8.09 & & & & \\
\hline
\end{tabular}

Tabel 7 Perhitungan Debit Banjir Metode Rasional

\begin{tabular}{|c|c|c|c|c|c|c|c|}
\hline $\begin{array}{c}n \\
\text { ( Tahun ) }\end{array}$ & $\begin{array}{c}R \\
(\mathrm{~mm})\end{array}$ & $\begin{array}{c}\mathrm{V} \\
(\mathrm{km} / \mathrm{jam})\end{array}$ & $\begin{array}{c}\mathrm{t} \\
(\mathrm{jam})\end{array}$ & $\begin{array}{c}\mathrm{r} \\
(\mathrm{mm} / \mathrm{jam})\end{array}$ & $\alpha$ & $\begin{array}{c}A \\
\left(\mathrm{~km}^{2}\right)\end{array}$ & $\begin{array}{c}Q_{n} \\
\left(\mathrm{~m}^{3} / \mathrm{det}\right)\end{array}$ \\
\hline 2 & 96.20 & 1.99 & 0.28 & 77.66 & 0.90 & 0.06 & 1.12 \\
\hline 5 & 136.10 & 1.99 & 0.28 & 109.87 & 0.90 & 0.06 & 1.59 \\
\hline 10 & 162.60 & 1.99 & 0.28 & 131.26 & 0.90 & 0.06 & 1.90 \\
\hline 20 & 182.60 & 1.99 & 0.28 & 147.40 & 0.90 & 0.06 & 2.13 \\
\hline 50 & 187.90 & 1.99 & 0.28 & 151.68 & 0.90 & 0.06 & 2.19 \\
\hline
\end{tabular}

Dari data-data yang ada disebutkan diatas, dengan luasan CA sebesar $\pm 6.0 \mathrm{Ha}\left(0.06 \mathrm{~km}^{2}\right)$, panjang saluran utama dalam gudang $\pm 0.6 \mathrm{~km}$, serta dengan menggunakan nilai koefisien limpasan (run off) sebesar 0.9 (mengingat perkembangan peruntukan lahan didaerah layanan sebagai pergudangan), maka besarnya debit banjir dengan metode rasional untuk periode ulang 10 tahun adalah sebesar $1.90 \mathrm{~m}^{3} / \mathrm{detik}$.

\section{III.5 Optimasi Potensi Kolam Retensi}

Kolam retensi yang merupakan bagian dari Sistem Penampungan Air Hujan (SPAH) adalah salah satu faktor utama dalam pengendalian banjir. Ketika suatu wilayah dikembangkan maka proporsi permukaan yang kedap air seperti atap dan perkerasan beton akan bertambah, sedangkan permukaan yang dapat menyerap air dan memungkinkan adanya infiltrasi seperti lapangan rumpur dan kebun menjadi berkurang.

Pengembangan suatu daerah harus menyerahkan rencana konsep drainase air hujan. Rencana tersebut harus menunjukkan dengan jelas kelayakan sistem drainase yang diusulkan dan hubungannya dengan sistem sub makro yang ada, sehingga tidak akan terjadi hambatan. Trase aliran air (baik aliran bawah tanah maupun aliran permukaan), ukuran dan lokasi dari SPAH harus masuk dalam rencana tersebut. Perhitungan kolam retensi rencana adalah sebagai berikut.

Volume air limpasan drainase dapat dihitung dengan menggunakan persamaan:

$V=\frac{Q m a k s}{2}(2 T c+T t)$

Dimana :

$\mathrm{V}=$ volume limpasan banjir $\left(\mathrm{m}^{3}\right)$ $\left(\mathrm{m}^{3} / \mathrm{s}\right)$

Qmaks = debit limpasan banjir maksimum

Tc = waktu konsentrasi banjir (jam)

$\mathrm{Tc}=0.0138 * \mathrm{~L} * \mathrm{i}^{-0.6}$

$\mathrm{L}=$ Panjang sungai $(\mathrm{km})$

$\mathrm{i}=$ kemiringan rerata sungai

$\mathrm{Tt}=$ waktu aliran dalam saluran (jam)

$\mathrm{Tt}=\mathrm{V} /(60 * \mathrm{~L})$

$\mathrm{V}=$ kecepatan aliran $(\mathrm{m} / \mathrm{s})$ asumsi $1.5 \mathrm{~m} / \mathrm{s}$

$\mathrm{L}=$ Panjang sungai $(\mathrm{m})$

Dengan demikian, perhitungan volume air limpasan drainase untuk periode ulang 10 tahun di pergudangan Pajang adalah sebagai berikut.

Qmaks $=1.90\left(\mathrm{~m}^{3} / \mathrm{s}\right)$

$\mathrm{Tc}=0.0138 * 0.6 * 0.0028^{-0.6}=0.28 \mathrm{jam}$

$\mathrm{Tt}=600 /(60 * 1.5)=6.67$ menit $=0.11 \mathrm{jam}$

$$
V=\frac{1.90}{2}(2(0.28)+(0.11))
$$

$\mathrm{V}=2,301.58 \mathrm{~m}^{3}$

Sehingga dapat ditentukan jika memiliki luasan tanah sebesar 1,200 $\mathrm{m}^{2}$ maka kedalaman kolam adalah $2 \mathrm{~m}$.

\section{III.6 Analisa Kapasitas Saluran}

Untuk menganalisa kapasitas saluran di Komplek Pergudangan Pajang, daerah tangkapan air dibagi menjadi beberapa sub-daerah tangkapan air agar permodelan menjadi lebih akurat. Wilayah rencana Kawasan Pergudangan Pajang dilalui oleh sungai sehingga dalam kajian luasan daerah tangkapan air diasumsikan mencakup lokasi rencana dan sekitarnya. Melalui pembagian sub-daerah tangkapan air juga dapat ditentukan pengaruh masing-masing sub-daerah tangkapan air terhadap saluran yang menjadi bahan kajian. Skema pemodelan Komplek Pergudangan Pajang yang daerah tangkapan airnya dibagi menjadi 22 sub-daerah dapat dilihat pada gambar 3. Garis yang tercetak tebal merupakan saluran.

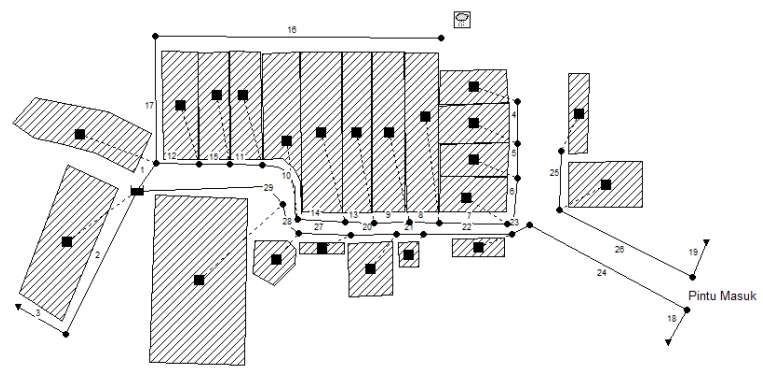

Gambar 3 Skema pemodelan komplek pergudangan Pajang

Fuad Hasan, R.H.B. Ash Siddiq, Yanyan Agustian

Jurnal Ilmiah Teknologi Informasi Terapan

Volume 6, No 3, 15 Agustus 2020 
Tabel 8 Perhitungan Debit Banjir Metode Rasional

\begin{tabular}{cccc}
\hline Kode Sub DTA & Luas $($ Ha) & Lebar DTA (m) & \%impervious \\
\hline \hline 6 & 0.1656 & 95 & 90 \\
7 & 0.1656 & 95 & 90 \\
8 & 0.1656 & 95 & 90 \\
9 & 0.1656 & 95 & 90 \\
10 & 0.2484 & 131 & 90 \\
11 & 0.2484 & 131 & 90 \\
12 & 0.2484 & 131 & 90 \\
13 & 0.2484 & 131 & 90 \\
14 & 0.1008 & 66 & 90 \\
15 & 0.1008 & 66 & 90 \\
16 & 0.1008 & 66 & 90 \\
17 & 0.1008 & 66 & 90 \\
23 & 0.3662 & 100 & 90 \\
33 & 0.2212 & 100 & 90 \\
35 & 0.0611 & 20 & 90 \\
36 & 0.033 & 23 & 90 \\
37 & 0.1020 & 23 & 90 \\
38 & 0.1825 & 15 & 90 \\
39 & 0.033 & 20 & 90 \\
40 & 0.1440 & 78 & 90 \\
41 & 0.0675 & 60 & 90 \\
44 (luar Gudang) & 3.93 & 500 & 80 \\
\hline Total Luas & $\mathbf{7 . 2}$ & Ha & \\
\hline \hline
\end{tabular}

Dalam pemodelan ini, geometri saluran merupakan geometri saluran rencana, karena sebelumnya saluran eksisting hanya sedikit. Saluran direncanakan berbentuk segiempat terbuka dengan lebar yang bermacam-macam sesuai dengan kebutuhannya.
Tabel 9 Data Geometri Saluran

\begin{tabular}{|c|c|c|c|c|c|c|c|}
\hline $\begin{array}{c}\text { Kode } \\
\text { Saluran }\end{array}$ & $\begin{array}{c}\text { Max. } \\
\text { Depth } \\
(\mathbf{m})\end{array}$ & $\begin{array}{c}\text { Lebar } \\
\text { Saluran } \\
(\mathbf{m})\end{array}$ & $\begin{array}{c}\text { Inlet } \\
\text { Node }\end{array}$ & $\begin{array}{c}\text { Outlet } \\
\text { Node }\end{array}$ & $\begin{array}{c}\text { Panjang } \\
\text { Saluran } \\
(\mathbf{m})\end{array}$ & Slope & Keterangan \\
\hline 1 & 1.00 & 1.00 & 2 & 3 & 39.50 & 0.0076 & $\begin{array}{c}\text { Rencana, } \\
\text { Main drain }\end{array}$ \\
\hline 2 & 1.00 & 1.00 & 3 & 4 & 97.74 & 0.0157 & $\begin{array}{c}\text { Rencana, } \\
\text { Main drain }\end{array}$ \\
\hline 3 & 0.50 & 0.50 & 4 & 5 & 66.65 & 0.0025 & Eksisting \\
\hline 4 & 0.50 & 0.50 & 22 & 21 & 24.00 & 0.0042 & Rencana \\
\hline 5 & 0.50 & 0.50 & 21 & 20 & 24.00 & 0.0013 & Rencana \\
\hline 6 & 0.50 & 0.50 & 20 & 18 & 24.00 & 0.0021 & Rencana \\
\hline 7 & 0.50 & 0.50 & 18 & 24 & 42.00 & 0.0003 & Rencana \\
\hline 8 & 0.50 & 0.50 & 24 & 25 & 23.00 & 0.0104 & Rencana \\
\hline 9 & 0.50 & 0.50 & 25 & 29 & 23.00 & 0.0087 & Rencana \\
\hline 10 & 0.60 & 0.60 & 26 & 27 & 25.00 & 0.004 & Rencana \\
\hline 11 & 0.60 & 0.60 & 27 & 31 & 23.00 & 0.0039 & Rencana \\
\hline 12 & 0.60 & 0.60 & 28 & 2 & 23.00 & 0.013 & Rencana \\
\hline 13 & 0.5 & 0.5 & 29 & 30 & 23.00 & 0.0009 & Rencana \\
\hline 14 & 0.6 & 0.6 & 30 & 26 & 23.00 & 0.01 & Rencana \\
\hline 15 & 0.6 & 0.6 & 31 & 28 & 23.00 & 0.0113 & Rencana \\
\hline 16 & 0.6 & 0.6 & 32 & 34 & 184.00 & 0.0056 & Rencana \\
\hline 17 & 0.6 & 0.6 & 34 & 2 & 72.00 & 0.0042 & Rencana \\
\hline 18 & 0.5 & 0.5 & 47 & 1 & 100.00 & 0.0013 & Eksisting \\
\hline 19 & 0.5 & 0.5 & 46 & 19 & 100.00 & 0.0013 & Eksisting \\
\hline 20 & 0.5 & 0.5 & 49 & 48 & 46.00 & 0.0004 & Rencana \\
\hline 21 & 0.5 & 0.5 & 50 & 49 & 23.00 & 0.0013 & Rencana \\
\hline 22 & 0.5 & 0.5 & 50 & 51 & 42.00 & 0.0388 & Rencana \\
\hline 23 & 0.5 & 0.5 & 51 & 45 & 23.00 & 0.062 & Rencana \\
\hline 24 & 0.3 & 0.3 & 45 & 47 & 73.50 & 0.0008 & Rencana \\
\hline 25 & 0.3 & 0.3 & 42 & 43 & 30.00 & 0.0403 & Rencana \\
\hline 26 & 0.3 & 0.3 & 43 & 46 & 61.00 & 0.017 & Rencana \\
\hline 27 & 0.5 & 0.5 & 48 & 52 & 23.00 & 0.0065 & Rencana \\
\hline 28 & 1.00 & 1.00 & 52 & 53 & 25.00 & 0.002 & Rencana \\
\hline 29 & 1.00 & 1.00 & 53 & 3 & 94.00 & 0.0133 & Eksisting \\
\hline & & & & & & & \\
\hline
\end{tabular}

Berdasarkan running pemodelan, didapat waktu puncak adalah pada jam ke 02:00. Kapasitas saluran pada masing-masing saluran saat waktu puncak dapat dilihat pada gambar 4. Debit maksimum pada saluran dapat dilihat pada tabel 10.

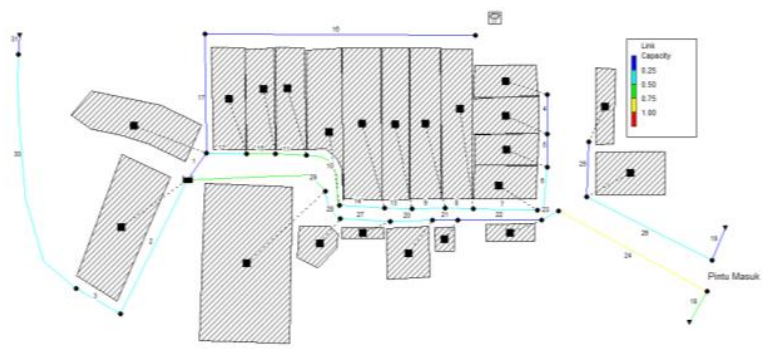

Gambar 4 Kapasitas saluran pada waktu puncak 
Berikut merupakan hidrograf yang masuk ke kolam retensi serta perubahan muka airnya.

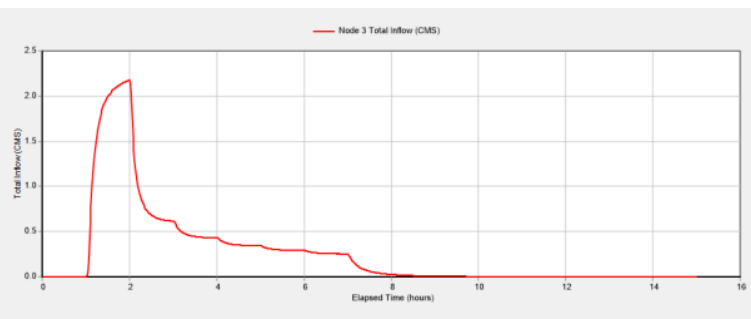

Gambar 5 Hidrograf inflow kolam retensi

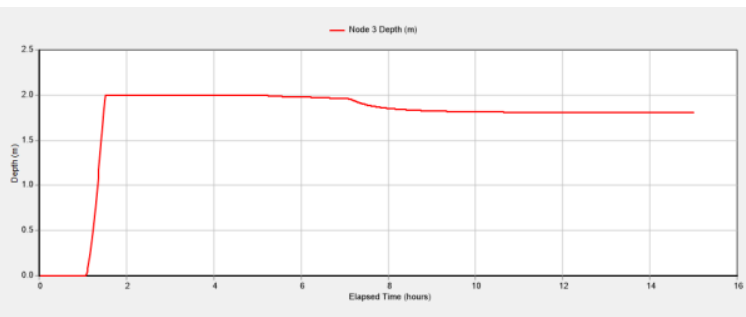

Gambar 6 Perubahan muka air di Kolam terhadap waktu

Berdasarkan hasil pemodelan diatas, dapat dilihat bahwa saluran area pergudangan masih mampu mengkapasitasi debit banjir yang terjadi akibat curah hujan periode ulang 10 tahun dengan besar debit maksimal yang masuk ke kolam retensi sebesar 2.18 $\mathrm{m}^{3} / \mathrm{s}$. Adapun ketinggian air maksimal di kolam berdasarkan hasil pemodelan adalah 2 meter, dan setelah mencapai waktu puncak ketinggian air menurun secara perlahan hingga mencapai ketinggian 1.7 meter.

Profil memanjang saluran dari kolam sampai dengan outlet gorong-gorong ke bandara SoekarnoHatta serta Debit yang mengalir pada masing-masing saluran dapat dilihat sebagai berikut.

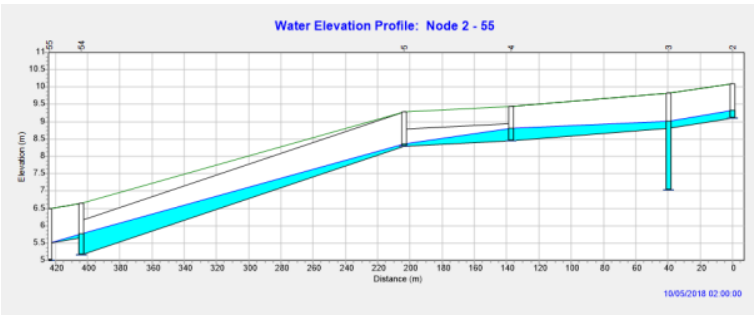

Gambar 7 Profil memanjang saluran dari kolam sampai outlet gorong - gorong
Tabel 10 Debit maksimum pada saluran

\begin{tabular}{|c|c|c|c|c|c|}
\hline Saluran & Debit $(\mathrm{m} 3 / \mathrm{s})$ & Saluran & Debit $(\mathrm{m} 3 / \mathrm{s})$ & Saluran & Debit $(\mathrm{m} 3 / \mathrm{s})$ \\
\hline 1 & 0.556 & 12 & 0.559 & 23 & 0.016 \\
\hline 2 & 0.336 & 13 & 0.28 & 24 & 0.052 \\
\hline 3 & 0.337 & 14 & 0.341 & 25 & 0.059 \\
\hline 4 & 0.025 & 15 & 0.462 & 26 & 0.059 \\
\hline 5 & 0.049 & 16 & 0 & 27 & 1.531 \\
\hline 6 & 0.074 & 17 & 0.006 & 28 & 0.141 \\
\hline 7 & 0.098 & 18 & 0.066 & 29 & 0.052 \\
\hline 8 & 0.159 & 19 & 0.091 & 30 & 0.336 \\
\hline 9 & 0.219 & 20 & 0.135 & 31 & 0.336 \\
\hline 10 & 0.381 & 21 & 0.166 & & \\
\hline 11 & 0.421 & 22 & 0.142 & & \\
\hline
\end{tabular}

Dari hasil pemodelan diatas dapat disimpulkan bahwa saluran outlet pergudangan masih dapat mengkapasitasi debit banjir yang terjadi.

\section{KESIMPULAN DAN SARAN}

Berdasarkan pemodelan yang sudah dilakukan dapat disimpulkan beberapa hal, di antaranya:

1. Jaringan saluran drainase yang dapat dibangun di Kompleks Pergudangan Pajang mengikuti skema permodelan pada Gambar 3.

2. Dimensi serta kemiringan saluran dapat mengikuti data pada tabel 9. (atau untuk dimensi saluran dapat diseragamkan).

3. Solusi yang dipilih untuk mengurangi dampak banjir adalah membuat kolam retensi dengan volume $2,400 \mathrm{~m}^{3}$

4. Agar kinerja kolam retensi optimal, maka kolam retensi harus dikosongkan oleh pompa, segera setelah puncak hujan terlewati atau badan air penerima pada level normal. Agar kinerja sistem pompa berfungsi maksimal, maka perlu dilaksanakan kegiatan operasi dan pemeliharaan yang benar. Secara sederhana pompa dinyalakan pada saat kolam penuh (kondisi badan air penerima pada level air normal) dan dimatikan pada saat kolam kosong.

5. Sungai Cibelendung (outlet) dan goronggorong menuju ke bandara Soekarno-Hatta masih dapat menampung debit banjir yang terjadi.

Fuad Hasan, R.H.B. Ash Siddiq, Yanyan Agustian 


\section{REFERENSI}

Triatmodjo B. 2010. Hidraulika II. Yogyakarta (ID): Beta Offset

Widodo E, Ningrum D. 2015. Evaluasi Sistem Jaringan Drainase Permukiman Soekarno Hatta Kota Malang dan Penanganannya. Jurnal Ilmu-Ilmu Teknik. 11(3):6-8

Hasan, Fuad, Bambang Eko Widyanto, Raden Herdian Bayu Ash Siddiq. 2020. Studi Respon Daerah Aliran Sungai Cimanyar Terhadap Berbagai Kejadian Hujan 